\title{
PREDIKSI RETAIL SALESMOBIL TOYOTA MENGGUNAKAN METODE ARIMA (AUTOREGRESSIVE INTEGRATED MOVING AVERAGE)
}

\author{
Adri Arisena \\ adriarisena@gmail.com \\ Program Studi Manajemen Institut ManajemenKoperasi Indonesia
}

\begin{abstract}
Abstrak
Penjualan mobil di Indonesia saat ini terus meningkat. Untuk melakukan perencanaan yang baik, perusahaan membutuhkan sebuah nilai prediksi penjualan agar dapat menentukan target penjualan mobil. Salah satu model prediksi yang sering digunakan untuk memprediksi sebuah data yaitu metode ARIMA (Autoregressive Integrated Moving Average). Dalam penelitian ini data yang digunakan yaitu data Retail Sales mobil Toyota dari bulan Januari 2017 sampai dengan Maret 2020. Retail Sales merupakan penjualan mobil dari dealer kepada konsumen sehingga diharapkan pabrik mobil Toyota memiliki prencanaan terhadap produksi mobil sehingga menjadi efektif dan efisien.
\end{abstract}

Kata Kunci : ARIMA, time series, Toyota, Mobil

\section{Abstrack}

Car sales in Indonesia are growing. To do good planning, the company needs a sales prediction value in order to determine the car sales target. One prediction model that is often used to predict a data is the method of ARIMA (Autoregressive Integrated Moving Average). In this study the data used is the Toyota Sales Retail data from January 2017 to March 2020. Retail Sales is a car sales from dealers to consumers, so it is hoped that the Toyota automobile factory has a preproduction to the automobile manufacturing so that it becomes effective and efficient.

Keywords : ARIMA, time series, Toyota, Car 


\section{Pendahuluan}

Transportasi merupakan perpindahan manusia atau barang dari satu tempat ketempat lainnya dengan menggunakan sebuah kendaraan yang digerakkan oleh manusia atau mesin. Saat ini transportasi sudah menjadi kebutuhan primer manusia untuk memudahkan pekerjaan manusia. Pentingnya peranan transportasi dalam kehidupan masyarakat Indonesia menjadikan industri dalam sektor ini harus terus dikembangkan dan diperhatikan demi kelangsungan pembangunan secara nasional maupun global. Salah satu transportasi yang sering digunakan terutama di Indonesia yaitu mobil. Mobil adalah kendaraan roda empat yang digerakkan dengan tenaga mesin dengan bahan bakar bensin atau solar yang mempunyai bentuk tertentu. Penjualan mobil di Indonesia saat ini cukup baik sehingga banyak produsen mobil mulai membuat pabriknya di Indonesia. Salah satu pabrik mobil di Indonesia yang sudah lama yaitu Toyota. Dalam menjalankan sebuah bisnis diperlukan sebuah perencanaan untuk menentukan sebuah target. Dalam hal ini akan dilakukan prediksi Retail Sales mobil Toyota pada tahun 2020. Retail Sales merupakan penjualan mobil dari dealer kepada konsumen sehingga perusahaan mampu membuat target produksi di pabrik sehingga dapat menekan biaya. Analisis yang digunakan yaitu dengan metode ARIMA (Autoregressive Integrated Moving Average).

Metode ARIMA merupakan metodeperamalan dengan menggunakan serang-kaian datamasa lalu yang digunakan untuk mengamatiterhadap suatu kejadian, peris-tiwa, atau suatuvariabel pada data tersebut (Makridakis 1998). Metode ini pertamakali dibuat oleh Box dan Jenkinsuntuk analisis deret berkala. ARIMA terbentuk daritiga metode yaitu AR (Autoregressive), MA (Moving Average), dan ARMA (Autoregressive and Moving Average). Kelebihan pada metode ARIMA ini adalah dapat digunakan untuk manganalisis situ-asi yang acak, tren, musim bahkan sifat siklis dalam deret waktu yang dianalisis.

\section{Tinjauan Pustaka}

Time Series merupakan kejadian-kejadian yang terjadi berdasarkan waktu-waktu tertentu secara berurutan.Forecasting dalam time series merupakan prediksi untuk memperkarakan kejadian-kejadian yang akan terjadidi masa yang akan datang berdasarkan data-data sebelumnya (Arif 2010). Salah satu model dalam time series adalah ARIMA.

Metode ARIMA sering juga disebut metode Box-Jenkins. ARIMA sangat baik ketepatannya untuk peramalan jangka pendek. Sedangkan untuk peramalan jangka panjang ketepatan peramalan ARIMA menjadi kurang baik. Ketepatan peramalan ARIMA menjadi kurang baik, dikarenakan hasil peramalan akan cenderung mendatar atau konstanuntuk periode jangka panjang (Box-Jenkin, 1994). ARIMA menggunakan nilai masa lalu dan sekarang dari variabel dependen untuk menghasilkan peramalan jangka pendek yang akurat. Bentuk umum dari model Non Seasonal ARIMA $(p, d, q)$ adalah model campuran antara Autoregressive (AR) orde $p$, dengan Moving Average (MA) orde $q$, dan differencing $d$. Adapun persamaan dari model Non Seasonal ARIMA $(p, d, q)$ dengan menggunakan backward shift operator (B) adalah sebagai berikut :

$$
(1-B)^{d} Y_{t}=\mu+\frac{\theta(B)}{\phi(B)} a_{t} \quad ; \mathrm{t}=1,2, \ldots, \mathrm{n}
$$

dengan

$$
\begin{aligned}
& Y_{t} \quad: \text { nilai data pada periode ke-t } \\
& \mu \quad \text { : nilai rata-rata } \\
& B \quad \text { : operator Backshift, dimana } \\
& B Y_{t}=Y_{t-1} \\
& \phi(B) \quad \text { : operator AR, dimana } \\
& \phi(B)=1-\sum_{i=1}^{p} \phi B^{i} \\
& \theta(B) \quad: \text { operator MA, dimana } \\
& \theta(B)=1-\sum_{i=1}^{q} \theta_{i} B^{i} \\
& a_{t} \quad: \text { kesalahan acak pada } \\
& \text { periode ke-t } \\
& n \quad \text { : banyaknyaobservasi }
\end{aligned}
$$




\section{Uji Stasioner}

Agar dapat melakukan estimasi suatu model dalam analisis data time series, langkah utama yang harus dilakukan adalah uji stasioneritas data. Suatu data deret waktu dikatakan stasioner apabila rata-rata, varians, dan autokovarians nilainya konstan dari waktu ke waktu. Dengan kata lain, ketiga ukuran tersebut tidaktergantung waktu. Data yang stasioner adalah data yang variansnya tidak terlalu besar dan mempunyai kecenderungan untuk mendekati nilai rata-ratanya. Suatu data dikatakan stasioner jika :

1. $E\left[Z_{t}\right]=\mu$, yaitu rata-rata dari $Z_{t}$

2. $\operatorname{Var}\left[Z_{t}\right]=E\left[Z_{t}-\mu\right]^{2}=\sigma^{2}$, yaitu varians dari $Z_{t}$ konstan

3. $\operatorname{Cov}\left[Z_{t}, Z_{t+k}\right]=E\left[\left(Z_{t}-\mu\right)\left(Z_{t+k}-\mu\right)\right]=\gamma_{k}$

, kovarians antara dua data time series hanya bergantung pada selang waktu $\mathrm{k}$ antara dua periode waktu tersebut. Selang waktu antara $Z_{t}$ dan $Z_{t+k}$ disebut lag (Wei, 2006)

Data dikatakan stasioner, jika mean ( $\left.E\left[Z_{t}\right]\right)$, variansi $\left(\operatorname{Var}\left[Z_{t}\right]\right)$, dan kovariansnya $\left(\operatorname{Cov}\left[Z_{t}, Z_{t+k}\right]\right)$ bersifat konstan. Hal ini berarti mean, varians dan kovariansnya tidak dipengaruhi oleh berubahnya waktu pengamatan, sehingga proses tersebut berada dalam keseimbangan secara statistik.

Uji akar unit merupakan salah satu pengujian untuk menentukan stasioneritas dalam suatu pemodelan autoregressive. Uji akar unit pada data deret waktu dengan model AR(p), dapat dilakukan dengan menggunakan uji Augmented Dicky-Fuller (ADF), yang dinyatakan dalam persamaan berikut :

$\Delta Z_{t}=\beta_{0}+\delta_{1} \Delta Z_{t-1}+\delta_{2} \Delta Z_{t-2}+\ldots+\delta_{p} \Delta Z_{t-p^{*}+1}+\varepsilon_{t}$

dengan

$\Delta Z_{t} \quad$ : diferensial pertama pada periode

ke- $t$

$\beta_{0} \quad$ : nilai konstan atau intercept

\section{$\delta_{i} \quad$ : koefisien regresi untuk lag}

diferensial pertama dari $\mathrm{Z}$

$\varepsilon_{t} \quad:$ error pada periode ke- $t$

$p^{*} \quad$ : jumlah lag

Uji persamaan AR(p) seperti pada Persamaan (2.2) disebut dengan persamaan Augmented Dicky-Fuller (ADF(k)), dengan $\mathrm{k}$ adalah jumlah lag. Langkah pengujian hipotesis ADF adalah sebagai berikut

Bentuk hipotesis penelitian adalah sebagai berikut :

$H_{o}: \delta^{*}=0$, (proses tidak stasioner)

$H_{1}: \delta^{*}<0$, (proses stasioner)

Bentuk statistik uji dari uji diatas adalah :

$t_{\delta}=\frac{\delta-\delta_{0}}{\operatorname{se}(\delta)}$ dengan $\operatorname{se}(\delta)$ adalah standar

error dari $\delta$

Kriteria Uji dan Kesimpulan

$H_{0}$ ditolak apabila $t_{\delta}<t_{\alpha}$ Dickey-Fuller, sehingga $Y_{t}$ adalah data deret waktu yang stasioner.

\section{Uji Ljung Box}

Model dikatakan baik jika deret residual $\left\{\varepsilon_{t}\right\}$ memenuhi syarat yaitu residual tidak berautokorelasi. Pengujian autokorelasi deret residual digunakan uji Q Ljung-Box dengan hipotesis sebagai berikut :

$H_{0} \quad: \quad \varepsilon_{1}=\ldots=\varepsilon_{k}=0 \quad$ (Residual data bersifat tidak berautokorelasi)

$H_{1} \quad$ : minimalsatutanda (=) tidakberlaku (Residual data bersifatautokorelasi)

Bentukstatistikuji :

$$
Q=T(T+2) \sum_{k=1}^{K} \frac{\rho_{k}^{2}}{(T-k)}
$$

Kriteria Uji : Tolak $H_{0}$ jika nilai $Q \geq \chi_{(\alpha, d f=K-p-q)}^{2}$

\section{Hasil dan Pembahasan}

Data yang digunakan dalam penelitian ini yaitu data Retail Sales mobil Toyota dari bulan Januari 2017 sampai dengan bulan Maret 2020. Software yang digunakan dalam penelitian ini yaitu Software R. Data 
di dapat dari website www.gaikindo.com. Adapun contoh struk-tur data ditampilkan pada Tabel berikut :

\section{Tabel 1}

\section{Retail Sales Mobil Toyota Periode Jan} 2017 s/d Maret 2020

\begin{tabular}{|c|l|c|}
\hline Tahun & Bulan & Penjualan \\
\hline \multirow{1}{*}{2017} & Januari & 31226 \\
\cline { 2 - 3 } & Februari & 29281 \\
\cline { 2 - 3 } & Maret & 33212 \\
\cline { 2 - 3 } & April & 30407 \\
\cline { 2 - 3 } & Mei & 33809 \\
\cline { 2 - 3 } & Juni & 27789 \\
\cline { 2 - 3 } & Juli & 29868 \\
\cline { 2 - 3 } & Agustus & 29949 \\
\cline { 2 - 3 } & September & 26621 \\
\cline { 2 - 3 } & Oktober & 29321 \\
\cline { 2 - 3 } & November & 33644 \\
\cline { 2 - 3 } & Desember & 34888 \\
\hline$\vdots$ & $\vdots$ & $\vdots$ \\
\hline \multirow{3}{*}{2020} & Januari & 24928 \\
\cline { 2 - 3 } & Februari & 23884 \\
\cline { 2 - 3 } & Maret & 17787 \\
\hline
\end{tabular}

Sumber :Gaikindo

\section{Uji Stasioneritas}

Dalam menggunakan metode ARIMA asumsi stasioneritas harus terpenuhi. Hasil pengujian asumsi stasioneritas adalah sebagaiberikut :

Augmented Dickey-Fuller Test

data: tsdata

Dickey-Fuller $=-3.7467$, Lag order $=3, \mathrm{p}$ value $=0.03467$

alternative hypothesis: stationary

Berdasarkan output tersebut dengan nilai alpha $=5 \%$ dapa tdisimpulkan bahwa data tersebut sudah stasioner. Hal tersebut dilihat dari nilai $\mathrm{p}$-value $=0.034$ lebih kecil daripada nilai alpha $=0.05$.

\section{Menentukan model ARIMA terbaik}

Setelah uji stasioner dilakukan kemudian menentukan model ARIMA terbaik dengan melihat nilai AIC. Adapun hasil output dari software $\mathrm{R}$ adalah sebagai berikut :

Series: tsdata

$\operatorname{ARIMA}(0,1,1)$
Coefficients:ma1 -0.8547

s.e. 0.0827

sigma^2 estimated as 13950302: $\log$

likelihood $=-366.64$

$\mathrm{AIC}=737.28 \quad \mathrm{AICc}=737.62 \quad \mathrm{BIC}=740.55$

Berdasarkan hasil output tersebut dapat dilihat bahwa model ARIMA terbaik dalam penelitian ini yaitu model ARIMA $(0,1,1)$ dengan nilai AIC 737,28

\section{Uji White Noise}

Setelah mendapatkan model ARIMA terbaik selanjutnya dilakukan Uji White Noise untuk melihat apakah residual dari model tidak mempunyai model tertentu. Adapun hasil output sebagai berikut :

Box-Ljung test data: res

$\mathrm{X}$-squared $=3.8656, \mathrm{df}=5, \mathrm{p}$-value $=$ 0.5689

Berdasarkan hasil output tersebut dapat dilihat bahwa nilai p-value lebih kecil dari nilai hitung yang artinya model residual memiliki model tertentu.

\section{Hasil Prediksi}

Setelah dilakukan tahapan ananlisis tersebut maka didapat hasil prediksi selama 9 bulan kedepan dari bulan April sampai dengan Desember 2020. Adapun hasil output sebagai berikut :

Point Forecast Lo 80 Hi 80 Lo 95 Hi 95

$40 \quad 26215.9221429 .3131002 .53$

18895.4333536 .41

$41 \quad 26215.9221379 .0731052 .77$

18818.6033613 .24

$42 \quad 26215.9221329 .3531102 .49$

18742.5633689 .28

$43 \quad 26215.9221280 .1331151 .71$

18667.2833764 .56

$44 \quad 26215.9221231 .4031200 .44$

18592.7533839 .09

$45 \quad 26215.9221183 .1331248 .70$

18518.9433912 .90

$46 \quad 26215.9221135 .3331296 .51$

18445.8333986 .01

$47 \quad 26215.9221087 .9731343 .86$

18373.4034058 .44

$48 \quad 26215.9221041 .0531390 .79$

18301.6434130 .20 
Berdasarkan hasil output tersebut dapat dilihat bahwa jika kita optimis dengan tingkat kepercayaan $95 \%$ maka dapat melihat kolom Hi 95. Jika melihat kolom tersebut maka Retail Sales Toyota tergolong baik dikarenakan prediksi tiap bulan meningkat. Namun jika pesimis dengan tingkat kepercayaan $95 \%$ maka dapat melihat kolom Lo 95. Jika ditampilkan dalam bentuk tabel maka sebagai berikut :

Tabel 2

HasilPrediksiRetail Sales Mobil Toyota Bulan April s/d Desember 2020

\begin{tabular}{|l|l|l|}
\hline \multicolumn{1}{|c|}{ Bulan } & \multicolumn{1}{c|}{$\begin{array}{c}\text { Lo 95 } \\
\text { (Pesimis) }\end{array}$} & \multicolumn{1}{c|}{$\begin{array}{c}\text { Hi 95 } \\
\text { (Optimis) }\end{array}$} \\
\hline April & 18895.43 & 33536.41 \\
\hline Mei & 18818.6 & 33613.24 \\
\hline Juni & 18742.56 & 33689.28 \\
\hline Juli & 18667.28 & 33764.56 \\
\hline Agustus & 18592.75 & 33839.09 \\
\hline September & 18518.94 & 33912.9 \\
\hline Oktober & 18445.83 & 33986.01 \\
\hline November & 18373.4 & 34058.44 \\
\hline Desember & 18301.64 & 34130.2 \\
\hline
\end{tabular}

Sumber:HasilAnalisis

\section{Kesimpulan}

Berdasarkan analisis tersebut dapat disimpulkan beberapa hal sebagai berikut :

1. Model ARIMA terbaik yang digunakan yaitu ARIMA $(0,1,1)$

2. Jika dilihat secara optimis dengan tingkat kepercayaan $95 \%$ maka Retail Sales mobil Toyota cenderung mengalami peningkatan penjualan.

\section{Saran}

Hasil tersebut dapat menjadi acuan untuk menentukan target produksi tiap bulan pada tahun 2020; Peneliti selanjutnya dapat menggunakan metode lain untukdata tersebut misalnya SARIMA;ARIMAX, dsb

\section{Daftar Pustaka}

Arif, (2011, November 12).Penerapan metode ARIMA dalam memprediksi temperatur udara. Retrieved November 12, 2011, fromhttp://arifzenki.wordpress.com/20 08/08/29/penerapan-metode-arima- dalam memprediksi-temperature-udara. Box, G.E.P., Jenkins, G.M. \& Reinsel, G.C. (1994). Time series analysis forcasting andcontrol ( $3^{\text {rd }}$ edition). Prentice Hall, EnglewoodClifs.

Makridakis, S., Wheelwright, S.C. \& Hyndman, R.J. (1998). Forcas-ting Methods andApplications ( $3^{\text {rd }}$ edition). United States of America: John Wiley \& Sons, Inc.

Wei, W.S. William, (2006). Time series analysis univariate and multivariate method. Pearson, New York. 